\title{
DISCUSSION.
}

\section{DARWINISM AND LOGIC: A REPLY TO PROFESSOR CREIGHTON.}

In his interesting paper, having the same title as this note, published in the Darwin Number, May, 1909, of this Review, Professor J. E. Creighton cites my work, Thought and Things, as representative of the Darwinian point of view in logic, and criticises it in some detail. I am, of course, gratified that the work is honored in this way. I find, however, that Professor Creighton's criticisms are not altogether valid, and I will accordingly suggest certain considerations which in my opinion show this.

Professor Creighton has no difficulty in showing by quotations from my different publications, that I am a Darwinian, and that Darwinian conceptions have had frequent application in my work; this I am making explicit enough in a little book on Darwin and the Humanities now in press. ${ }^{1}$ Nor has he greater difficulty in showing that I often take the standpoint from which experience is looked upon as an immanent self-integrating movement. But he considers these two points of view inconsistent with each other: one interprets experience 'biologically' - as a relation of organism and mind to environment - the other 'logically' or 'teleologically' ( so Professor Creighton) - as a principle of internal organization and movement. The question then is this : can both of these points of view be held at once? - or does either commit us to a philosophy which excludes the other?

Evidently the first, the method and view-point of biological science, must be upheld if we are to have a theory of mental development and evolution at all. Each mind grows up in a body, and both mind and body are in environments. Experience requires things and situations: its own movement establishes and utilizes what we call the ' trans-subjective reference.' Is the 1ecognition of this consistent with a theory which interprets experience as a progressive organization having its own 'logic'?

Professor Creighton thinks that the latter point of view commits one to a 'teleology' which - though somewhat vague to me - seems to require the denial of the validity of a Darwinian conception of

${ }^{1}$ Review Publishing Co., Baltimore. 
adaptation, considered as a necessary factor in the development of experience. ${ }^{1}$

Proceeding then to the criticism of my views, made by Professor Creighton, I may say that it is in my last work alone, the 'Genetic Logic,' that I have taken exclusively the point of view of experience. It should not be compared with the other more biological books and papers except as this difference is recognized.

In the Genetic Logic the attempt is made to trace out the actual movement of experience from mode to mode, all of these modes being equally 'psychic.' The result is reached that a dualism of controls, due to segregation of contents, is come upon in experience itself. This dualism is not injected by our interpretation, nor read in from an external point of view: it is found by and in the process. The important point is that by its own immanental movement into the logical mode, experience establishes just the dualism that science adopts and employs. In the discussion of the relation of the 'psychic' and 'objective' points of view (Thought and Things, I., chap. II., §§3, 4), I show that the latter is simply the explicit outcome of the dualism normally established when the mode of judgment or reflection is reached. ${ }^{3}$ The scientific is simply the logical point of view made use of as deliberate method. It involves the self judging or thinking and objects judged about or observed - objects known to it as ' things.' This very dualism is the presupposition of the logical as such; and scientific method - whether its results issue in Darwinism, Lamarckism, vitalism, mechanism, teleology or any other type of theory - is

'He uses the expression 'genetic or teleological' as if these two terms were synonymous (p. 185).

${ }^{2}$ It is a conscious and deliberate difference, and cannot be looked apon as a contradiction unless it can be shown that one of the points of view is rendered invalid when one takes the other. In the Social Interpretations both methods are used on occasion, to supplement and confirm each other, the biological howerer having a very subordinate place. In the Genetic Logic, the standpoint of experience, the 'psychic' point of view, is consistently maintained. It is erroneous, therefore, to say (Creighton, p. 180), "Professor Baldwin's account professes to show, not how the mind becomes conscions of its own logical nature, but how that logical nature is engendered in it through the motor adjustments of the organism to material conditions." How the mind becomes [grows to be] conscious of its logical nature [or processes] is just what the Genetic Logic does profess to show.

'Instead of allowing Professor Creighton's interpretation to the effect that the 'inner and outer controls' are in my hands 'a translation into other terms of the organism and environment,' I hold that the relation of organism and environment is a logical transformation of the dualism of inner and outer controls. 
thinking, no more and no less than thinking. In the more refined operations of thought upon ideas, the ideas are symbols of the things into which they are at any time convertible. The sciences of observation go directly to the things, to perceptions and sensations; but in both cases the control of the context, whether it be one of ideas or of things, is the same - that of a sphere taken by the process to be foreign to itself.

So far then from finding a contradiction between the point of view of evolution - dualistic as it is - and that of a truly psychic account of the genesis of knowledge, I find that the latter issues in and justifies the former. Any adequate tracing out of the progression of knowledge, within experience itself, shows it to issue in a system of judgments in which the two controls - things as 'outer' and the self as 'inner' - are found confronting each other. Reflection sublimates this dualism by erecting a mediating context of ideas; but all validities in the context and all truthful references beyond it, rest upon the fact that this mediation is dual.

What then I would insist upon is the radically unreal character of the supposed contradiction. The observation, experimentation, analysis, etc., of biological science, as of all science, are processes proper and vital to the logical mode of experience. Science is logical process proceeding under its normal and necessary presuppositions. In recognizing the externality of things - the environment - it is only following the essential movement of psychic process, which although presupposing externality, still finds it to be a meaning of contrast with the internality of the inner control, of the self. Accordingly, one may freely use the biological method and point of view (as I have done in the paper on 'selective thinking' which Professor Creighton considers very reprehensible in this respect); for this procedure only recognizes as valid, for purposes of deliberate observation, the dualism that logical experience itself establishes for all the processes of thought. ${ }^{1}$

Of course, the further question will be asked : Is one's final philosophical view then to be dualistic? - is logical experience to be taken at its word and as the final word? Professor Creighton, as just cited, says that I recognize only two alternatives, mechanism and apriorism; and he suggests the third, teleology. But my recognition of these two modes of interpretation is merely to cite them as horns of a

It is clear then that the following statement of my view is not correct (Creighton, p. I84), "here as elsewhere the alternative for Professor Baldwin is between deriving logical principles mechanically and finding them existing a priori" (italics his). 
dilemma both of which are to be avoided. ${ }^{1}$ The teleological interpretation, also, taken in its ordinary sense - barring its excessive ambiguity - is also to be questioned, and for much the same reasons. These reasons I may now briefly state.

1. We are only remaining true to the standpoint of experience itself in seeking to trace out the rise and development of such categories as mechanism and teleology. They arise as meanings attaching to different sorts of experience; and by them objects and situations are consistently and profitably apprehended and treated. Some experiences have a certain regularity and lawfulness: these, thus apprehended, come to mean the mechanical. In the case of other experiences, developing conation shapes the contents toward personal ends : these, so apprehended, mean the teleological. In the logical mode, these two meanings become general ways of assimilating events of one type or the other. Each is valid for its purpose, and each is restricted in its use: one means to experience just the dominance of external, the other that of internal control.

Now to use either of these as an exclusive or universal mode of interpretation is to abolish the other in its own province, and so to falsify our report of the progression of experience in which they have together arisen. The mechanical would not be mechanical but for the possession of those characters which show it to be bare of teleological meaning; it represents knowledge formed under a control which evidences itself as foreign. The teleological, on the other hand, would not be teleological but for its character as embodying the agent's control exercised in the pursuit of personal ends. Teleological processes as such are for consciousness not mechanical, and mechanical are not teleological.

I have contrasted the results of these two modes of process by using the two expressions ' knowledge through (external) control' - issuing in sequences which are mechanical in their meaning - and '(internal) control through knowledge' - issuing in sequences with which personal interest and conation are identified (Thought and Things, II., chap. XIV.). Unless the teleologists can show, from the movement of further experience, that there is positive justification

${ }^{1}$ I do not accept the term 'mechanism' as applicable to a genetic movement proper; it denotes only one of the possible naturalistic interpretations of this movement. My own interpretation, embodied in the theory of 'genetic modes,' combats the mechanical view.

'The following has reference also to Professor Creighton's paper read at Baltimore to which I listened. It may suggest to him some revision of that paper, since this discussion is new. 
for the step, ${ }^{1}$ they may not employ as a universal solvent the partial meaning which they favor.

2. But even if we allow the category of teleology to apply universally, it also issues in a characteristic dualism from which there is no logical escape. Ends are attained through the mediation of ideas or facts. Facts and ideas are not ends: " what a man hath why doth he yet hope for ?' - it is a further realization, beyond the idea or fact, that he hopes for. A conscious end is always meditated - furthered or hindered - by some fact or idea. To any teleology which involves genuine purpose, the dualism of 'fact-idea and end' - taking the form of 'means and end' or of 'hindrance to end' - is as stubborn as that of 'thinker and thing' in the domain of cognition.

To escape this difficulty, the intellectual idealist goes over to a teleology which does not involve purpose in any concrete or actual sense, while he still retains vaguely the principle of 'means and ends.' But what ' means and ends' can mean apart from an agent who adopts the means (facts or ideas) to attain the ends (results), it is difficult to see. What is really present is the actual flow of genetic process, with its great dualisms of knowledge and purpose. If we take this process for what it is, it discovers itself to experience in the two modes of organization called teleological or mechanical according as the situations of actual life present contents of one sort or the other. ${ }^{2}$

${ }^{1}$ Actually the progress of experience, both personal and racial, is away from animistic and anthropomorphic teleological interpretations of nature. Science has had gradually to achieve its birthright, only gradually establishing a conception of natural law which operates without 'teleological' interference. Just here is, in fact, in my opinion, the great service rendered by Darwinism to philosophical thought : it once for all established a natural law of adaptation.

'In my discussion of 'genetic series' as such (the theory of 'Genetic Modes,' Development and Evolution, chap. XIX., described by Professor Creighton as a sort of invalid compromise), I bave pointed out that such series present both aspects, the quantitative or mechanical and the qualitative or in the large sense 'worthful': they show a form of sequence or conditioning which is not exhausted by either interpretation taken alone. Professor Creighton is, I think, in errorin saying (p. 182) about this theory that 'the something new' that it recognizes as arising in a genetic series 'simply comes into the series as a miracle.' I reply : it is not a miracle except to one who has already adopted a quantitative or mechanical conception of all natural change. Such a cast-iron quantitative conception apart - why should not nature produce novelties? James and Bergson, as well as the present writer, have recently protested against the arid 'energistic' conception of ' cause and effect.' For my part, I am not willing to prejudice the case by using the terms of mechanics for such sequences; I have employed the term 'progression.' . . . Further, I do not admit Professor Creighton's claim that a genetic series, as I conceive it, in my theory of 'genetic 
If this actual genetic movement, so apprehended in experience the progressive integration of contents, as on occasion both 'factual' and ' end-fulfilling' for the agent, is what Professor Creighton means by 'teleology' - then I am with him. I prefer that term to 'mechanism,' if one is to use but one term for the entire movement. But my aim is to go further constructively, and to discover what the issue is when the movement does not stop with the mediation by ideas in either of these two ways - with mediation as true for knowledge, and as good for purpose - but when it goes on to apprehend the contents in a further mode of direct contemplation. The movement then goes beyond the objectification of the contents in judgments of fact and value; and reaches a higher hyper-logical immediacy. ${ }^{1}$ My present purpose is accomplished, however, in showing how it is possible to turn the edge of Professor Creighton's criticism. I accept both the terms of the supposed contradiction. I hold that when legitimately employed both mechanism and teleology are naturalistic or empirical categories, both valid, but both restricted, in their proper use, and both superseded in a hyper-logical mode of experience.

6 Avinde Matignon,

J. Mark Baldwin.

PARIS.

modes,' 'exhibits no identity throughout the different stages of the process.' On the contrary, the varying degrees of identity which it actually has for consciousness serve as motive to the transformations of the 'sameness' meaning, as traced in my book in great detail, up to the logical judgment of identity (Vol. I., chap. VIII., \&3, and chap. IX., \& 5 ; Vol. II., chap. X.).

${ }^{2}$ To the development of this point much of the third volume of the Genetic Logic is to be devoted. In an article entitled 'Knowledge and Imagination,' Psychologrcal REVIF, May, I908, I have stated in outline the characters in virtue of which esthetic experience appears to discharge this office. 